Aletria, Belo Horizonte, v. 28, n. 3, p. 149-162, 2018

\title{
As catábases virgilianas (Geórgicas IV e Eneida VI): omniauincit amor ${ }^{1}$
}

\section{The Virgilians' Catabasis (Georgics IV and Aeneid VI): Omniauincit Amor}

\author{
Heloísa Maria Moraes Moreira Penna \\ Universidade Federal de Minas Gerais, Belo Horizonte, Minas Gerais / Brasil \\ heloisampenna@hotmail.com
}

Resumo: No livro IV das Geórgicas, em dois painéis narrativos, o pastor Aristeu e o poeta Orfeu realizam uma jornada pessoal em busca de alcançar objetivos distintos e com resultados bem diversos. Um paralelo de opostos pode ser traçado entre os dois heróis, que vai desde a descida a mundos inacessíveis até a subida ad auras superas com resultados antagônicos. Dentro da visão da totalidade e do continuum da obra virgiliana, a viagem transcendental desses dois personagens prenuncia a catábase de Eneias, no livro VI. Pode-se, então, verificar uma oposição entre Eneias e Orfeu e, por outro lado, uma aproximação entre Eneias e Aristeu. As Geórgicas, como obra do meio da carreira do poeta Virgílio, figura o deus de duas faces Jano: olha para o futuro (a Eneida) sem perder de vista o passado (as Bucólicas).

Palavras-chave: catábases; Geórgicas IV; Orfeu; Aristeu; Eneias; Eneida VI.

Abstract: In The Georgics: Book IV, in two parallel narratives, the shepherd Aristeus and the poet Orpheus embark on different personal journeys. In the context of the Virgilian work, the transcendental journey of these two characters foreshadows the catabasis (descent to hell) of Aeneas in The Aeneid: Book VI. Marking the midpoint of Virgil's career, The Georgics, like the journeys of Aristeus and Orpheus, represents the two-faced god Janus insofar as the work anticipates the production of The Aeneid without losing sight of the past (The Bucolics).

Keywords: catabasis; Georgics IV; Orpheus; Aristeu; Aeneas, Aeneid VI.

\footnotetext{
${ }^{1}$ Este artigo é uma das produções de meu Pós-Doc feito na Unicamp sob a orientação do Prof. Dr. Paulo Sérgio de Vasconcelos, professor de língua e literatura latina do Instituto de Estudos da Linguagem.
} 


\section{Introdução}

A descida ao submundo, catábase, é uma das provas a ser cumprida pelo herói mítico, em sua desafiadora jornada pelo mundo. Aconteceu com Orfeu, Pólux, Teseu, Odisseu e Eneias, só para citar os relacionados pelo poeta Virgílio, no canto VI da Eneida. ${ }^{2}$ Esses heróis desceram ao perigoso submundo da morte, apesar de vivos, e conseguiram retornar. Mas a catábase pode acontecer, também, em outro ambiente, diferente do tradicional e em franco contraste com o reino tenebroso, "o mundo romântico de Cyrene, sob as águas do Peneu". ${ }^{3} \mathrm{O}$ pastor Aristeu, um mestre na Arcádia (Arcadius magister) e personagem do IV livro das Geórgicas, em missão nobre, visita a "corte subaquática" de sua mãe, realiza uma catábase à origem das águas, ${ }^{4}$ para pedir auxílio de um problema sem solução para a capacidade humana: a misteriosa perda de sua colmeia. A ele é exigida essa e outras provas por ter causado a morte de Eurídice, a catábase de Orfeu e a consequente morte do poeta, por desmembramento. A maior das provas que Aristeu deve realizar é a submissão de Proteu, o velho deus do mar. Pode-se considerar essa uma segunda etapa de sua catábase, que consistiu na preparação do herói para a luta: a mãe espalhou em seu corpo perfume de ambrosia (liquidum ambrosiae diffundit odorem) ${ }^{5}$ na chegada a uma grande caverna (specus ingens), esculpida na lateral de um monte, no modelo da caverna da Sibila na Eneida VI, v. 236 - Spelunca alta, immanis, morada de Proteu e no uso de força e coragem. Aí ele vivencia, pela narrativa do deus, a tragédia de Orfeu, como Eneias vivencia, pelas palavras de Anquises, os sofrimentos e as lutas dos Romanos na construção de seu Império.

\footnotetext{
${ }^{2}$ si potuit manes arcessere coniugis Orpheus, / Treicia fretus cithara fidibusque canoris; I si fratrem Pollux alterna morte redemit, / itque reditque uiam totiens: quid Thesea, magnum / quid memorem Alcidem? Et mi genus ab Ioue summo (Se Orfeu pôde buscar os manes da esposa, / confiado na trácia cítara e nas cordas canoras; / se Pólux remiu, com morte alternada, seu irmão, / e foi e voltou no caminho muitas vezes; por que de Teseu e por que / do grande Alcides me lembraria? Para mim, há a descendência de Júpiter supremo) (VIRGILIO. Eneida VI, vv. 119-123). Todas as traduções, do latim e de outras línguas, são de minha autoria.

3 "romantic world of Cyrene under the Waters of Peneus" (WILKINSON. The Georgics of Virgil: A Critical Survey, p. 72).

4 "catabasi all'origine delle acque" (CONTE. Virgilio: Il genere e i suoi confini, p. 48).

${ }^{5}$ VIRGIL. Georgics, v. 415.
} 
Temos então três catábases, narradas pelo poeta Virgílio, que têm em comum uma busca obstinada, tendo o amor, em suas múltiplas concepções, como motivador: o amor da honra e do louvor motiva Aristeu, modelo de agricultor (amor honoris et laudis); o amor pela esposa impulsiona Orfeu, modelo de poeta (amor coniugis); e o amor pelo dever religioso, familiar e político orienta Eneias, modelo de civilizador $^{6}$ (amor pietatis). O famoso verso 69, da X Bucólica, omnia uincit amor: et nos cedamus amori (o amor vence todas as coisas: assim, cedamos ao amor), provaram ser proverbiais também para as catábases das Geórgicas IV e da Eneida VI. Nesse caso, eles são complementares da máxima geórgica, proveniente do livro I (Geórgicas I, vv. 145-146), labor omnia uicit improbus (o labor venceu, ousado, todas as coisas), que tão bem expressa o espírito de todo o livro. Orfeu, no entanto, por ter sido desmemoriado - immemor, heu! -, transformou sua descida num episódio de glória e perdição, triunfo e perda definitiva: todo o trabalho foi desfeito por uma falha trágica, quebra de aliança com o deus do submundo - Ib(i) omnis / effusus laboratqu(e) immitis rupta tyranni / foedera... (Então, todo o esforço se perdeu e rompeu-se o pacto com o indócil tirano..., Geórgicas IV, vv. 491-493). Afinal, Orfeu não apenas possuiu o amor, mas foi totalmente possuído por ele. Albrecht assim resume o tema de amor nas três obras virgilianas: nas Éclogas, "paixão que subjuga tudo"; nas Geórgicas, "uma força violenta na vida dos animais", exceto no mundo particular das abelhas e, no caso de Orfeu, "está em conexão com as temáticas sobre a vida e a morte e sobre o poder e a ineficácia do canto"; na Eneida, "o amor está representado como destino", uma tragédia de dimensões heroicas. ${ }^{7}$

\section{As três catábases e suas personagens: aproximações possíveis}

Essas três narrativas-catábases vêm em sequência na obra virgiliana. As duas primeiras, de Aristeu e Orfeu, nas Geórgicas IV, a

\footnotetext{
6 "Aeneas is the moral archetype of the civilization" (PUTNAM. Essays on Latin Lyric, Elegy and Epic, p. 341).

7 "passión que sojuzga todo"; "una fuerza violenta en la vida de los animales"; "está en conexión con las temáticas sobre la vida y la muerte y sobre el poder y la ineficacia del canto"; "el amor está representado como destino" (ALBRECHT. Historia de la Literatura Romana desde Andrónico hasta Boecio, p. 645).
} 
terceira, de Eneias, na Eneida VI. Percebe-se nitidamente que o nível de complexidade das narrativas vai aumentando, sugerindo um crescente entre as obras do autor que vai da poesia pastoril à poesia épica, o que, estilisticamente, significa sair do estilo humilde em direção ao sublime. ${ }^{8}$ Assim é que temos, na Eneida VI (vv. 123-125), pela boca da Sibila, uma sentença sobre os requisitos dessa prova, palavra final sobre o tema. Segundo ela, realizar a catábase não é a missão mais difícil. Retornar incólume, eis o grande desafio! A descida ao Averno é fácil (facilis descensus Averno, v. 126), pois noite e dia a porta do atro Dite está aberta (noctes atque dies patet atri ianua Ditis, v. 127), mas retornar os passos e sair para o mundo superior (sed revocare gradum superasque evadere ad auras, v. 128), eis o trabalho e a grande dificuldade (hoc opus, hic labor est, v. 129). São poucos os que o justo Júpiter amou de verdade ou a ardente virtude permitiu o retorno (pauci, quos aequus amavit Iuppiter aut ardens evexit ad aethera virtus, vv. 129-130). Essa talvez seja a explicação para o insucesso de Orfeu que, na verdade, numa leitura figurativa do mito, nunca retornou, de fato, do além-túmulo. A não aceitação da morte da esposa, a desobediência aos deuses infernais, o amor demasiado a um único ser, certamente fazem dele um homem cuja virtude não arde - indigno, portanto, do amor de Júpiter. Além disso, Orfeu foi tomado pelo furor, uma paixão destrutiva que também está presente na Eneida, consumindo "as nobres figuras de Dido e Turno". 9

Aristeu, apesar de personagem das Geórgicas, obra de cunho didático, é apontado como épico, em contraste com Orfeu, pelos traços próprios e contextuais. Otis aponta, além da questão formal, traços que considera obviamente épicos de Aristeu: faz longo e elaborado discurso; atinge locais reservados aos deuses, como a corte subaquática de Cyrene e a caverna de Proteu; enfrenta desafios sobre-humanos e está rodeado de grandiosas figuras, epicamente adjetivadas: os vales de Tempe no Peneu (Peneia Tempe), Apolo do monte Thymbreu (Thymbraeus Apollo), Ásia da ninfa Deiopea (Asia Deiopea), mar purpúreo (mare purpureum),

\footnotetext{
${ }^{8}$ HARDIE. Virgil, p. 1. Hardie chama de teleologia poética de Virgílio essa carreira literária pré-determinada, que vai do humilde (ficcional) pastoreio, passando pelo prático e realista assunto das Geórgicas e culminando na histórica e política épica. Isso tudo sem perder a unidade do conjunto em conformidade com o processo histórico romano. 9 "It will consume the noble figures of Dido and Turnus" (LEE. Virgil as Orpheus: A Study of the Georgics, p. 125).
} 
incenso da Panchaia (Panchaei ignes), a deusa Vesta em chamas (ardens Vesta), o avançado em anos, Nereu (grandaeuos Nereus). ${ }^{10}$

Por outro lado, o mesmo Otis considera que a história de Orfeu, "primeiro grande exemplo de um novo estilo","1 está muito ligado à Eneida, em seu livro IV, embora não sendo épica. Além disso, a perda da esposa Eurídice evoca a perda de Creúsa, narrada no final do livro II da Eneida, conforme observado por Vasconcelos: "Virgílio nos estimula a comparar - e confrontar - as situações por que passam um e outro através da alusão contínua". ${ }^{12}$

Mas o que têm em comum Aristeu, Orfeu e Eneias, além da descida para mundos apenas permitidos a deuses e semideuses? Primeiro o parentesco com as divindades, daí a permissão para a catábase: Aristeu, filho de Apolo; Orfeu, filho de, segundo as Geórgicas, "Egreu, um rei lendário e rio-deus da Tessália"; ${ }^{13}$ e Eneias, filho de Vênus. Em segundo lugar, suas histórias de perdas: Aristeu perde suas abelhas, "que representam sua inteira realização"; ${ }^{14}$ Orfeu perde Eurídice, razão de sua vida, e a si próprio tragicamente; Eneias perde sua pátria, sua esposa e seu pai.

Todos eles são personagens da tradição épica que Virgílio selecionou em duas de suas inúmeras fontes, Homero e Apolônio de Rodes. Aristeu aparece na Ilíada e na Odisseia; Orfeu é um dos passageiros do navio Argos; e Eneias tem sua apresentação feita na Ilíada, XX. Além disso, são heróis culturais, conforme nomeia Conte a Aristeu e a Orfeu e que se pode estender, sem qualquer dificuldade, para Eneias. Segundo Conte, sem levar em consideração a complexidade mítica das duas figuras e a supremacia de Orfeu, "Aristeu se move exclusivamente na esfera agrícola e promove atividade civilizatória como o pastoreio e a apicultura; Orfeu é inventor da música e da poesia e, neste âmbito,

\footnotetext{
${ }^{10}$ Cf. OTIS. Virgil, A Study in Civilized Poetry, p. 194.

11 "as a whole, the Orpheus is the first great example of a new style" (OTIS. Virgil, A Study in Civilized Poetry, p. 208).

${ }^{12}$ VASCONCELOS. Efeitos intertextuais na Eneida de Virgílio, p. 149.

13 "Oeagrius, a legendary king and river god of Thessaly" (MILES. Virgil's Georgics: A New Interpretation, p. 273).

14 "Aristeus loses his bees, which represent his entire achievement" (ROSS. Virgil's Elements: Physics and Poetry in the Georgics, p. 214).
} 
favorece também ele a passagem do estado primitivo àquele civilizado". ${ }^{15}$ Eneias é um herói fundador de cidades e tem a missão de organizar o mundo civilizado, após o desastre da guerra de Troia.

Há ainda, rondando suas estórias, a intrigante figura do deus Apolo, deus da doença e da cura; da paz e da guerra. Horácio no II livro das Odes (II, 10, 16-20) caracteriza o deus como o que alterna o arco com a cítara: quondam cithara tacentem / suscitat Musam neque semper arcum / tendit Apollo (Apolo, algumas vezes, com a cítara, desperta a calada Musa e nem sempre o arco empunha). Nos lamentos dos heróis, ele aparece direta ou indiretamente. Aristeu é filho de Apolo e se serve dessa paternidade para reivindicar seus direitos de semideus, nas margens do rio Peneu, morada de sua mãe Cyrene (pater est Thymbraeus Apollo - meu pai é o tymbreu Apolo); Orfeu, nas Geórgicas, não é filho de Apolo, mas, como o deus, possui o dom divino da música e seu lamento é sempre na lira (ipse caua solans aegrum testudin(e) amorem, v. 464 - Ele mesmo, para consolar seu doído amor na curva lira), e, por fim, Eneias tem Apolo como protetor dos troianos e dirige a ele um apelo, antes da descida aos Infernos (Phoebe, gravis Troiae semper miserate labores, v. 56 - Febo, que sempre compadeceu dos graves trabalhos de Troia).

\section{Aristeu e Eneias: heróis da coletividade}

Ao traçar um paralelo da busca da imortalidade entre Aristeu e Otaviano, no proêmio e sphragis do livro IV das Geórgicas, Gale ${ }^{16}$ nos leva a pensar num paralelo entre Aristeu e Eneias, já que a identificação desse herói épico com Otaviano é, frequentemente, cogitada. Miles aproxima Aristeu e César como heróis por "desempenharem a aparentemente impossível tarefa de substituir uma sociedade arruinada por uma nova". ${ }^{17}$ Há também a questão do pensamento coletivo: Aristeu quer recuperar sua colmeia e, para tal, irá adquirir uma técnica de grande valor para a

15 “Aristeo si muove esclusivamente nella esfera agricola e promuove attività civilizzatrici come La pastorizia e l'apicoltura; Orfeo èl'inventore dela musica e dela poesia, e in questo ambito favorische anch'egli Il trapasso dallo stato primitivo a quello civilizzato" (CONTE. Virgilio: Il genere e i suoi confini, p. 46).

${ }^{16} \mathrm{Cf}$. GALE. Virgil on the Nature of Things: The Georgics, Lucretius and the Didactic Tradition, p. 325.

17 " [...] by performing the seemingly impossible task of replacing a ruined society with a new one" (MILES. Virgil's: A New Interpretation, p. 291). 
comunidade, devido à importância do mel como alimento e remédio. Eneias quer cumprir sua missão divina de refundar Troia e ser o patriarca de uma grande descendência. A força de Aristeu e Eneias provém de suas fraquezas traduzidas pela insegurança e incerteza do futuro. São heróis humanizados, longe do guerreiro idealizado. Há choro e desespero em suas trajetórias: para Eneias as lágrimas do improbus labor (duro trabalho), na busca de nova pátria; para Aristeu, no resgate da colmeia perdida. Há, para ambos, a intervenção de uma mãe divina que os ajuda e aconselha; ambos são fundadores, segundo Griffin e, ambos receberam um legado, não apenas para si, mas para a coletividade: Aristeu recebeu a arte da Bugonia, "de recuperar perdidos paruos Quirites [pequenos Quirites] [...] uma arte como a prometida ao Romano por Anquises - hae tibi erunt artes". ${ }^{18} \mathrm{O}$ texto virgiliano, realçando a coletividade na missão de Eneias, segue explicando as artes próprias dos romanos: pacique imponere morem, parcere subiectis et debellare superbos, vv. 852-853 (não só impor preceitos de paz mas também poupar os subjugados e debelar os soberbos).

\section{Aristeu e Orfeu: Labor x Amor}

O que mais comumente vemos é o estudo contrastivo entre Aristeu e Orfeu, por suas evidentes diferenças. Aqui também se pode citar o embate metapoético dos gêneros épico e elegíaco, dentro das Geórgicas IV, com Orfeu sendo a grande referência do poeta elegíaco e Aristeu a do poeta do epos. Seu imenso amor por Eurídice o impulsiona a uma jornada épica quando "inicia sua Katabasis, não como Aristeu para dentro da água e ressoante alameda, mas para dentro do bosque sombrio da morte". ${ }^{19}$

Gale afirma que ambos "refletem muito das tensões que percorrem o poema". ${ }^{20}$ Aristeu é, segundo ela, um agricultor prático que cultiva cereais, árvores e vinhas e cuida de abelhas. Dócil aos ensinamentos e à aplicação das regras, sua "insegurança" de humilde agricultor é sua

18 "[...] one of regaining lost paruos Quirites [...] an ars like that promise to the Roman by Anquises - haec tibi erunt artes" (GRIFFIN. The Fourth Georgic, Virgil and Rome, p. 239).

19 "The epic journey begins as Orpheus initiates his Katabasis, not like Aristaeus into water and resounding grove but into death's dark copse (467-70)" (PUTNAM. Virgil's Poem of the Earth: Studies in the Georgics, p. 295).

20 "reflects many of the tensions wich run through the poem" (GALE. Virgil on the Nature of Things: The Georgics, Lucretius and the Didactic Tradition, p. 52). 
força. Orfeu é um poeta e amante com rasgos de arrogância. A missão de Aristeu, resgatar o enxame perdido, é em benefício da posteridade; a de Orfeu é individualista, satisfazer ao seu desejo de perda. Eurídice é o único tema de sua canção. "A força do poeta é também sua fraqueza". ${ }^{21}$ Aristeu cumpre as ordens, tanto em relação à captura de Proteu quanto ao ritualístico modus orandi (modo de orar), na celebração da Bugonia. Sua serenidade lhe permite avançar, sem retroceder. Orfeu, por outro lado, está sujeito ao furor e à dementia, que o leva a desobedecer aos divinos comandos, avança, mas não alcança o desejado. Para Conte, a diferença entre os dois personagens está nas atitudes e modo de vida de cada um: "de um lado, o georgós, escrupuloso e pio; de outro, o amante [...] traído pelo furor que o anima". ${ }^{22}$

Para Morgan, "Orfeu representa um ethos oposto do tipo geral descrito no idílio pastoral", ${ }^{23}$ é um escravo do amor que o leva à morte, pelas mãos das mulheres trácias.

Miles, tomando partido de Orfeu, chama a atenção para a "perturbadora amoralidade" de Aristeu, ${ }^{24}$ que, embora tenha causado a morte de Eurídice, não sente qualquer remorso. Prova disso, segundo ele, seria a petulância em seu lamento que não inclui qualquer referência a essa morte, mas apenas a perda de suas abelhas e reputação. Para Miles, os sentimentos de Orfeu são mais autênticos, pois ele, ao contrário de Aristeu, valoriza a perda de Eurídice, como única e insubstituível: "não pode haver substituta para Eurídice; ele canta por ela e dela somente". ${ }^{25}$ Já Aristeu pensa apenas em si mesmo e lamenta não por amor às abelhas, mas por considerar-se menor sem elas.

Batstone vê muito em comum entre Aristeu e Orfeu, sem pender para uma ou outra figura. Segundo sua leitura, "ambas são apaixonadas,

21 "The poet's strength is also his weakness" (GALE. Virgil on the Nature of Things: The Georgics, Lucretius and the Didactic Tradition, p. 53).

22 “da um lato Il georgós scrupuloso e pio, dall'altro l'amante che - seppure armato della forza trascinante e sconvolgente di Eros - è però tradito da quello stesso furor che lo anima" (CONTE. Virgilio: Il genere e i suoi confini, p. 47).

23 "Orpheus represents an opposite ethos of the general kind depicted in the pastoral idyll at the end of G.2”. (MORGAN. Patterns of Redemption in Virgil's 'Georgics', p. 170). 24 “disturbing amorality" (MILES. Virgil's Georgics: A New Interpretation. p. 271). 25 "There can be no substitute for his Eurydice; he sings of her and of her alone" (MILES. Virgil's Georgics: A New Interpretation, p. 271-272). 
imersas em si mesmo e destrutivas dos outros; ambas destroem Eurídice, mas permanecem indiferentes à culpa", ${ }^{26}$

Por fim, Aristeu como estadista e Orfeu como poeta, leva-nos, com Hardie, ${ }^{27}$ a refletir sobre a oposição final, registrada ludicamente na sphragis do livro IV das Geórgicas, entre César Otaviano, em nome de Roma, empreendendo guerra junto ao Eufrates e o poeta Virgílio, em ocioso "combate" literário nos litorais napolitanos.

\section{Eneias e Orfeu: redenção e castigo}

A catábase de Orfeu, nas Geórgicas IV, é um ensaio à de Eneias, na Eneida VI. A entrada no submundo e o encontro com as almas deixam muito próximos os dois textos. Além disso, a par das diferenças de objetivos dos dois personagens, Eneias buscando conhecimento para chegar a seu destino e Orfeu procurando pela esposa, há, para os dois, enorme sentimento de perda, quando da descida aos infernos: Eneias perdera sua pátria, sua esposa, e seu pai; e levara ao suicídio a rainha Dido, desesperada com o desprezo do amado. Orfeu perdera sua jovem esposa, razão de sua vida e canção. Mas as aproximações param por aí, pois as cores dos dois personagens são demasiado contrastivas. "Orfeu, cantor do amor perdido, vivendo e morrendo inteiramente para a arte e o amor, de um lado e, de outro, o velho romano, non sibi sed patriae natus" (nascido não para si, mas para a pátria). ${ }^{28}$ Porém, a simpatia que Orfeu inspira no poeta Virgílio, apesar da impiedosa e direta narrativa de Proteu, pode ser testemunhada na Eneida VI, vv. 645-647, em que o Orfeu se encontra pacificado nos Campos dos Bem-aventurados: nec non Threicius longa cum veste sacerdos obloquitur numeris septem discrimina vocum, iamque eadem digitis, iam pectine pulsat eburno. (E o sacerdote Trácio, com sua longa veste, acompanha, com o canto, a lira de sete cordas, e, ora a toca com os dedos, ora com a palheta de marfim).

26 " [...] both are passionate, self-absorbed, and destructive of others; both destroy Eurydice but remain indifferent to guilt" (BATSTONE. Virgilian Didaxis: Value and Meaning in the Georgics, p. 127).

${ }^{27}$ Cf. HARDIE. Virgil, p. 48.

28 "the lover-lorn singer Orpheus, living and dying entirely for art and love, on the other side, the old Roman, non sibi sed patriae natus [...]" (GRIFFIN. The Fourth Georgic, Virgil and Rome, p. 237). 
O que nos interessa, pois, no confronto entre esses dois personagens, não é tanto sua caracterização de herói, mas a descrição de suas catábases que, embora sucinta nas Geórgicas, antecipa a grande narração do livro VI da Eneida. Della Corte ${ }^{29}$ destaca passagens da épica virgiliana em que há ampliação, transposição fiel ou leve modificação dos trechos das Geórgicas. Como exemplo de transposição ipsis litteris tem-se os versos das Geórgicas IV, vv. 475-477 e da Eneida, da descrição das almas atraídas por Orfeu e Eneias: "assim mães, maridos e corpos sem vida / de magnânimos heróis, rapazes e moças solteiras / e jovens dispostos nas piras, nas vistas dos pais". ${ }^{30}$ Para transposição levemente modificada, com a substituição, na Eneida do adjetivo tristes que acompanha palus por tarda, tem-se nas Geórgicas IV, os versos 479480, e na Eneida VI, vv. 438-439 ("e o pântano odioso por estagnadas / tristes águas / e o Estige que os prende em suas nove voltas"). ${ }^{31}$ Para ampliação, apresenta-se o trecho com o símile das aves nas Geórgicas IV, vv. 473-474, "22 "qual milhares de aves que se amontoam nos galhos, / quando Vésper ou a chuva de inverno as afugenta dos montes"; e na Eneida VI, vv. 309-312,33 "qual muitas folhas deslizantes, caem, nas matas, no primeiro frio do outono, ou para a terra, do alto mar, tantas muitas aves lançam-se em turbilhões, quando a fria estação as afugenta de além-mar e as envia a terras quentes".

Partindo desse conceito de ampliação, pode-se sugerir que o livro VI da Eneida é um desenvolvimento do episódio da catábase de Orfeu nas Geórgicas IV, e que o inferno de Orfeu é uma antecipação do de Eneias. A Eneida VI funciona ainda como um livro de consulta, uma enciclopédia para os termos apresentados, só de passagem, na catábase de Orfeu, nas Geórgicas IV. Morrone, na introdução de seus comentários ao livro VI da Eneida, confirmando a completude e complexidade filosófico-teológica

${ }^{29}$ Cf. DELLA CORTE. Le Georgique di Virgilio: Libri III - IV, p. 95.

${ }^{30}$ Matres atque viri defunctaque corpora vita / magnanimum heroum, pueri innuptaeque puellae, / Impositique rogis iuvenes ante ora parentum (Eneida VI, vv. 306-308).

${ }^{31}$ tardaque (Eneida VI, vv. 438-439) / tristisque (Geórgicas IV, vv. 479-480) palus inamabilis unda / alligat et nouiens Styx interfusa coercet.

${ }^{32}$ Quam multa in foliis avium se milia condunt/vesper ubi aut hibernus agit de montibus imber (Geórgicas IV, vv. 473-474).

${ }^{33}$ Quam multa in silvis autumni frigore primo / lapsa cadunt folia, aut ad terram gurgite ab alto / quam multae glomerantur aves, ubi frigidus annus / trans pontum fugat et terris immittit apricis (Eneida VI, vv. 309-312) 
de origem pitagórica e platônica do livro, delineia a estrutura do Inferno virgiliano em três partes, momentos que explicitam, segundo ele, "os três motivos dominantes da personalidade do herói [...] e os três temas fundamentais da concepção do poema": ${ }^{34}$ o Pré-Inferno; o Inferno; e o Elísio. Assim, o lucus, as fauces, as ostia Ditis, primeiros elementos da representação topográfica dos Infernos, mencionados em dois versos das Geórgicas IV (467-468), são desenvolvidos na Eneida na parte do Pré-Inferno: "zona que se estende do vestíbulo até o rio do Aqueronte, onde se agitam os insepultos". ${ }^{35}$ A passagem por essa região engloba 143 versos (267 a 410), com descrições dos lugares, diálogos com os espíritos conhecidos, com a Sibila e o barqueiro Caronte. Inclusive a "consulta" à Eneida ao vocábulo portitor Orci (porteiro do Orco), do verso 502 das Geórgicas IV, trará uma detalhada descrição física (vv. 296-304) do barqueiro Caronte e de sua função (vv. 388-397). A menção feita em um único verso, nas Geórgicas (v. 471), às sedes mais íntimas, sedes imae, aos Tártaros, Tartara (v. 481), às Eumenides, a Cerberus (v. 483) e à roda de Ixião, Ixionii rota (v. 484) encontra-se desenvolvida na Eneida na grande parte do Inferno, propriamente dito, com 234 versos (411 a 645):

que é compreendido pelo Aqueronte e pelo Flegetonte, entre os quais se estendem, de uma parte, os Campos das Lágrimas, reino de Minos, e sede dos que morreram por um ou outro motivo, prematuramente; de outra, entre o cerco dúplice do rio de fogo e do muro, o Tártaro, reino de Radamanto e sede dos grandes reis. ${ }^{36}$

Da mesma forma, o motivo da impossibilidade do contato físico com as almas, por sua natureza etérea (fumus in auras commixtus tenuis - fumaça misturada com o etéreo ar) e do desejo das mesmas em realizá-lo (tendens inualidas palmas - estendendo as inválidas mãos), que aparecem nos versos 498-502 das Geórgicas IV, é desenvolvido, mais tarde, na Eneida II (tenuis in auras - para o etéreo ar), quando

\footnotetext{
34 “ter motivi dominant della personalità dell'eroe [...] I trê temi fondamentali della concezione del poema" (MORRONE in Eneida: Liber VI, p. IV).

${ }^{35}$ MORRONE in Eneida: Liber VI, p. VI.

${ }^{36}$ MORRONE in Eneida: Liber VI, p. VI.
} 
Eneias tenta abraçar a imagem de Creúsa por três vezes; ${ }^{37}$ e, na Eneida VI, vv. 699-702, na tentativa de abraçar seu pai Anquises, os três versos se repetem ipsis litteris. Na Eneida VI, v. 314, tem-se o motivo das mãos estendidas ao barqueiro Caronte: as almas da margem ulterior estendiam as mãos, avidamente (tendebant manus rip(ae) ulterioris amore).

\section{Conclusão: transformação após catábase}

A experiência da catábase, na saga do herói, é, em sua maioria, positiva. Tomando como exemplo as catábases aqui analisadas, as de Aristeu, Orfeu e Eneias, duas delas serviram de auxílio para caminhada futura do personagem e uma delas, a de Orfeu, não promoveu a transformação necessária ao poeta-cantor e, contrariamente, o levou à destruição. Mesmo porque, pode-se especular: o ideal do poeta elegíaco é estar com sua amada, ainda que na morte. Aristeu, como Eneias, saiu fortalecido, aprendeu com essa experiência, sobre o passado e o futuro. ${ }^{38}$

A catábase de Aristeu ao mundo subaquático de Cyrene se estende também à sua visita à gruta de Proteu. A viagem só se completa após a vitória sobre esse deus marinho. Aliás, o amadurecimento intelectual e emocional, necessário a Aristeu, tem início com uma narrativa catártica: morte de Eurídice, catábase de Orfeu, perda de Eurídice, tristeza redobrada de Orfeu, morte violenta de Orfeu. Após isso, Aristeu "está pronto para aprender e crescer", "sua maturação está completa!" " Eneias também visualiza, na narrativa de Anquises, muita dor e sofrimento libertadores.

Assim é que testemunhamos a maestria do poeta Virgílio que provou, em suas obras, dominar os segredos da vida após a morte e desvendar para seus leitores o poder da imortalidade literária. Com amor e labor o poeta venceu todas as coisas!

\footnotetext{
${ }^{37}$ ter conatus ibi collo dare brachia circum / ter frustra comprensa manus effugit imago / par leuibus uentis uolucrique similima somno (por três vezes tentou levar os braços ao redor do pescoço; por três vezes a imagem furtou-se ao toque da mão / tal qual as leves brisas e parecidíssimo com o volátil sono) (Eneida VI, vv. 790-794).

38 "Like Aeneas he must learn of past and future" (PUTNAM. Virgil's Poem of the Earth: Studies in the Georgics, p. 286).

39 "He is ready to learn and grow"; "Aristeus'maturing is complete" (LEE. Virgil as Orpheus: A Study of the Georgics, p. 122-123).
} 


\section{Referências}

ALBRECHT, Michael Von. Historia de la Literatura Romana desde Andrónico hasta Boecio. Versión castellana por los doctors Dulce Estefanía y Andrés Pociña Pérez. Barcelona: Herder, 1997. v. 1.

BATSTONE, William. Virgilian Didaxis: Value and Meaning in the Georgics. In: MARTINDALE, Charles (Ed.) The Cambridge Companion to Virgil. Cambridge: Cambridge University Press, 1997. p. 125-144.

CONTE, Gian Baggio. Virgilio: Il genere e i suoi confini. Itália: Garzanti, 1984.

DELLA CORTE, Francesco. Le Georgiche di Virgilio: Libri III - IV. Commentate e tradotte da Francesco Della Corte. Genova: Instituto de Filologia Classica e Medievale, 1986.

GALE, Monica R. Virgil on the Nature of Things: The Georgics, Lucretius and the Didactic Tradition. Cambridge: Cambridge University Press, 2000 .

GRIFFIN. The Fourth Georgic, Virgil and Rome. In VOLK, Katharina (Ed.). Oxford Reading in Classical Studies Vergil's Georgics. Oxford: Oxford University Press, 2008. p. 225-248.

HARDIE, Philip. Virgil. Oxford: Oxford University Press, 1998. (Greece \& Rome: New Surveys in the Classics, 28)

LEE, M. Owen. Virgil as Orpheus: A Study of the Georgics. Albany: State University of New York Press, 1996.

MILES, Gary B. Virgil's Georgics: A New Interpretation. California: University of California Press, 1980.

MORGAN, Llewelyn. Patterns of Redemption in Virgil's Georgics. Cambridge: Cambridge University Press, 1999

MORRONE, Gino. Introduzione. In: VIRGILIO. Eneida: Liber VI. Roma: Perrella, 1949. p. iv-vi.

OTIS, Brooks. Virgil, A Study in Civilized Poetry. Norman, OK: University of Oklahoma Press, 1995.

PUTNAM, Michael C. J. Essays on Latin Lyric, Elegy and Epic. Princeton: Princeton University Press, 1982. 
PUTNAM, Michael C. J. Virgil's Poem of the Earth: Studies in the Georgics. Princeton: Princeton University Press, 1979.

ROSS, David O. Virgil's Elements: Physics and Poetry in the Georgics. New Jersey: Princeton University Press, 1987.

VASCONCELOS, Paulo Sérgio. Efeitos intertextuais na Eneida de Virgílio. São Paulo: Humanitas, 2001.

VIRGIL. Georgics. Books III-IV. Edited by Richard F. Thomas. Cambridge: University Press, 1988. v. 2.

VIRGÍLIO. Eneida brasileira ou tradução poética da Epopeia de Públio Virgílio Maro. Organização de Paulo Sérgio de Vasconcelos et al. Campinas: Editora da Unicamp, 2008.

VIRGILIO. Eneida: Liber VI. Con introduzione e commento di Gino Morrone. Roma: Perrella, 1949.

WILKINSON, L. P. The Georgics of Virgil: A Critical Survey. Norman, OK: University of Oklahoma Press, 1997. 